\title{
Comportamento ingestivo, consumo e digestibilidade de nutrientes, produção e composição do leite de vacas alimentadas com silagem de milho ou cana-de-açúcar com caroço de algodão ${ }^{1}$
}

\author{
Daniel de Paula Sousa ${ }^{2 *}$, José Maurício de Souza Campos ${ }^{3}$, Sebastião de Campos \\ Valadares Filho ${ }^{3}$, Rogério de Paula Lana ${ }^{3}$, Camilla Atsumi Zanuncio Sediyama ${ }^{4}$, Josué \\ Mendes Neto ${ }^{2}$
}

\footnotetext{
${ }^{1}$ Pesquisa financiada pela Fundação de Amparo à Pesquisa do Estado de Minas Gerais.

2 Programa de Pós-Graduação em Zootecnia - Universidade Federal de Viçosa.

${ }^{3}$ Departamento de Zootecnia - Universidade Federal de Viçosa.

${ }^{4}$ Curso de Agronomia - Universidade Federal de Viçosa.
}

RESUMO - Doze vacas foram distribuídas em três quadrados latinos $4 \times 4$ com o objetivo de avaliar o consumo e a digestibilidade aparente dos nutrientes, a produção e a composição do leite e o comportamento ingestivo. Os tratamentos consistiram de silagem de milho ou cana-de-açúcar contendo 0,7 ou 14\% de caroço de algodão. Na relação volumoso:concentrado estabelecida, 60:40, o tratamento silagem de milho foi superior na maioria dos parâmetros avaliados, como consumo de MS (20,8 kg/dia), produção de leite e leite corrigida para gordura (25,0 e 27,0 kg/dia) e produções diárias de gordura e proteína (984 e 772 g/dia). O tratamento cana-de-açúcar com 7\% de caroço de algodão aumentou o consumo de MS (17,1 vs 15,5 kg/dia) e tanto o tratamento cana-de-açúcar com $7 \%$ quanto com $14 \%$ promoveram aumentos nos consumos de extrato etéreo (0,41 e 0,59 vs 0,24 kg/dia), carboidratos não-fibrosos (7,4 e 7,3 vs 6,7 kg/dia) e NDT (11,6 e 11,9 vs 10,4 kg/dia) em comparação à cana-de-açúcar sem caroço de algodão. Os maiores consumos de nutrientes propiciaram aumentos na produção de leite (19,7 e 20,6 vs 18,6 kg/dia), de leite corrigida para gordura (21,1 e 21,6 vs 18,9 kg/dia) e nas produções diárias de gordura (771 e 781 vs 664 g/dia) e proteína (602 e 625 vs 565 g/dia) pelos dois níveis de inclusão em comparação ao tratamento sem caroço de algodão, respectivamente. O tratamento com $14 \%$ de caroço algodão apresentou variação de peso negativa (-0,22 kg/dia), maior tempo em ruminação que o tratamento cana-de-açúcar sem caroço de algodão e tendênica de menores consumos de MS e nutrientes em relação à cana-de-açúcar com 7\% de caroço de algodão. Considerando os resultados obtidos nesta pesquisa, o uso e a indicação de dietas com maiores teores de caroço de algodão devem ser analisados com cautela.

Palavras-chave: eficiência de alimentação, eficiência de ruminação, línter, mastigação

\section{Feeding behavior, feed intake and digestibility, milk composition and production of cows fed maize silage or sugarcane with whole cottonseed}

ABSTRACT - Twelve cows were allotted to three $4 \times 4$ latin squares to evaluate intake and apparent digestibility of nutrients, milk composition and production and feeding behavior. The treatments consisted of maize silage or sugarcane with 0,7 or $14 \%$ of whole cottonseed. In the established forage:concentrate ratio of 60:40, the corn silage treatment was superior for most of parameters evaluated including dry matter intake $(20.8 \mathrm{~kg} / \mathrm{d})$, milk and fat corrected milk production (25.0 and $27.0 \mathrm{~kg} / \mathrm{d}$ ) and daily production of fat and protein (984 and $772 \mathrm{~g} / \mathrm{d})$. Sugarcane with $7 \%$ of whole cottonseed treatment increased DM intake (17.1 vs. $15.5 \mathrm{~kg} / \mathrm{d})$ and sugarcane treatments with both $7 \%$ and $14 \%$ increased the intakes of ether extract ( 0.41 and 0.59 vs $0.24 \mathrm{~kg} / \mathrm{dia}$ ), non fibrous carbohydrate ( 7.4 and 7.3 vs $6.7 \mathrm{~kg} / \mathrm{d}$ ) and NDT (11.6 and 11.9 vs $10.4 \mathrm{~kg} / \mathrm{d}$ ) compared to sugarcane without whole cottonseed treatment. The higher intake of nutrients resulted in increases in milk production (19.7 and 20.6 vs $18.6 \mathrm{~kg} / \mathrm{d}$ ), fat corrected milk production (21.1 and $21.6 \mathrm{vs} 18.9 \mathrm{~kg} / \mathrm{d}$ ) and daily fat (771 and $781 \mathrm{vs} 664 \mathrm{~g} / \mathrm{d}$ ) and protein production (602 and $625 \mathrm{vs} 565 \mathrm{~g} / \mathrm{d}$ ) by the two levels compared to sugarcane without whole cottonseed treatment, respectively. Sugarcane with $14 \%$ whole cottonseed treatment presented negative weight variation $(-0.22 \mathrm{~kg} / \mathrm{d})$, larger period in rumination activity than sugarcane without whole cottonseed, tendency of lower dry matter and nutrient intake than sugarcane with $7 \%$ whole cottonseed. By the data presented, the use and recommendation of larger whole cottonseed content diets should be analyzed with care.

Key Words: feeding efficiency, linter, mastigation, rumination efficiency 


\section{Introdução}

A silagem de milho é uma das tecnologias importadas das regiões de clima temperado utilizadas na maioria dos sistemas de produção de leite como alternativa de suplementação durante o período da seca, ou até mesmo durante todo o ano (Nussio, 1993). Entretanto, apesar das inúmeras vantagens do uso da silagem de milho, esta tecnologia demanda consideráveis custos em recursos técnicos e financeiros.

A utilização da cana-de-açúcar como forragem na alimentação de bovinos tem como vantagens a alta produtividade de massa verde ( 80 a $120 \mathrm{t} / \mathrm{ha}$ ), o baixo custo por unidade de matéria seca (MS), a manutenção do valor nutritivo até seis meses após a maturação e o período de colheita coincidente com o período de escassez de forragem nas pastagens (Silva, 1993). No entanto, o baixo teor proteico, a fibra de baixa degradação ruminal, o desbalanço de minerais e o pequeno aporte pós-ruminal de aminoácidos e glicose dificultam o uso da cana-de-açúcar na dieta de animais (Preston, 1982).

As limitações da cana-de-açúcar fazem com que seu uso em dietas reduza o consumo em vacas leiteiras, promovendo desempenhos inferiores aos obtidos com a silagem de milho, o que restringe seu uso na alimentação de vacas de alta produção (Dado \& Allen, 1995). Entretanto, estudos têm comprovado que a cana-de-açúcar apresenta valores similares aos da silagem de milho para produções de leite de vacas de média produção quando o nível de concentrado é maior que 50\% (Mendonça et al., 2004) ou um mínimo de 60\% para que não ocorra perda de peso corporal (Rodrigues, 1999; Costa et al., 2005).

Dessa forma, a utilização de subprodutos da agroindústria, como o caroço de algodão, pode reduzir o custo do concentrado e viabilizar o uso da cana-de-açúcar. Esse subproduto reúne características desejáveis para sua incorporação na alimentação de ruminantes. Esse alimento apresenta alto teor de proteína e de energia (20\% PB; 23\% de extrato etéreo; 82,86\% de NDT (Valadares Filho et al., 2002), possui fibra efetiva de grande digestibilidade (Harvatine et al., 2002) e não requer qualquer processamento.

Considerando a fibra efetiva de boa qualidade e a alta concentração energética, o caroço de algodão pode substituir com vantagens parte da fração volumosa da dieta, no caso, a cana-de-açúcar (Pires et al., 1997). Estudos comprovam que há pouco efeito sobre o consumo quando até $18,5 \%$ de caroço de algodão foram adicionados nas dietas (Hawkins et al., 1985), variando de 15\% (Arieli, 1998) até 25\% (Coppock et al., 1985) as recomendações de adição nas dietas.
Neste contexto, este trabalho foi realizado com o objetivo de avaliar os efeitos da substituição parcial da cana-de-açúcar pelo caroço de algodão em comparação à dieta à base de silagem de milho sobre a produção e composição do leite, o consumo e a digestibilidade dos nutrientes da dieta e o comportamento ingestivo de vacas leiteiras.

\section{Material e Métodos}

O experimento foi conduzido no período de agosto a outubro de 2001 utilizando-se 12 vacas multíparas lactantes, 7/8 Holandês Gir, com aproximadamente 70 dias em lactação, distribuídas em três quadrados latinos $4 \times 4$. Os critérios para alocação dos animais em cada quadrado latino foram a produção de leite atual, a produção na lactação anterior, o peso, o estágio de lactação e o número de parições.

O experimento foi constituído de quatro períodos de 21 dias, de modo que os 14 primeiros foram de adaptação às dietas e os 7 posteriores de coleta. Os animais utilizados no experimento foram manejados em baias individuais, tipo Tie Stall e alimentados e ordenhados duas vezes ao dia, com controle diário da oferta e das sobras de alimentos. As dietas foram formuladas segundo recomendações do NRC (2001) para atender às necessidades de vacas produzindo $25 \mathrm{~kg}$ /dia de leite e continham aproximadamente 37 a $40 \%$ de FDN e 15\% de PB (Tabela 1).

Em uma das dietas, o volumoso utilizado foi silagem de milho (Zea mays), enquanto, nos demais, o volumoso oferecido foi cana-de-açúcar (Saccharum officinarum, L) com 0,7 ou $14 \%$ de caroço de algodão na matéria seca total, correspondendo a consumos médios diários de 0 ; 1,50 e 3,00 kg de caroço de algodão, respectivamente. A relação volumoso:concentrado em todas as dietas foi 60:40 com base na matéria seca, considerando o caroço de algodão como volumoso. Nas dietas à base a cana-deaçúcar, corrigiu-se o teor proteico por meio da adição de 1\% da mistura ureia+sulfato de amônio (SA) na proporção 9:1, respectivamente, com base na matéria natural da cana-de-açúcar.

A coleta de amostras de fezes para estimar a excreção fecal e determinar a digestibilidade aparente dos nutrientes foi realizada nos últimos cinco dias do período experimental (Craig et al., 1984). Utilizou-se como marcador interno FDA indigestível (FDAi) e, para sua determinação, amostras dos alimentos fornecidos, das sobras e das fezes foram incubadas por 144 horas no rúmen de vacas alimentadas com 60:40 de volumoso e concentrado em sacos de Ankom (Ankom ${ }^{\circledR}$ filter). 
Tabela 1 - Proporção e composição bromatológica dos ingredientes das dietas

\begin{tabular}{|c|c|c|c|c|}
\hline \multirow[t]{2}{*}{ Item } & \multirow[t]{2}{*}{ Silagem de milho } & \multicolumn{3}{|c|}{ Nível de caroço de algodão na cana-de-açúcar } \\
\hline & & $0 \%$ & $7 \%$ & $14 \%$ \\
\hline \multicolumn{5}{|l|}{ Composição em ingredientes, \% MS } \\
\hline Cana-de-açúcar & - & 60,00 & 53,00 & 46,00 \\
\hline Caroço de algodão & - & - & 7,00 & 14,00 \\
\hline Fubá de milho & 20,30 & 24,88 & 27,19 & 29,51 \\
\hline Uréia+sulfato de amônia & 0,60 & 0,6 & 0,53 & 0,46 \\
\hline Suplemento mineral & 1,30 & 1,75 & 1,75 & 1,74 \\
\hline \multicolumn{5}{|l|}{ Composição química } \\
\hline Matéria seca (\%) & 53,57 & 52,17 & 55,84 & 59,45 \\
\hline Matéria orgânica (\% MS) & 94,15 & 95,93 & 95,79 & 96,04 \\
\hline Extrato etéreo (\% MS) & 2,10 & 1,34 & 2,35 & 3,76 \\
\hline Carboidratos totais (\% MS) & 76,69 & 79,60 & 78,35 & 77,70 \\
\hline Carbohidratos não-fibrosos (\% MS) & 36,65 & 41,59 & 41,04 & 40,69 \\
\hline Fibra em detergente neutro (\% MS) & 40,04 & 38,01 & 37,31 & 37,01 \\
\hline $\mathrm{FDN}_{\mathrm{CP}}(\% \mathrm{MS})$ & 38,34 & 36,55 & 35,94 & 35,30 \\
\hline Fibra em detergente ácido (\% MS) & 20,83 & 23,10 & 22,65 & 22,65 \\
\hline Lignina (\% MS) & 4,21 & 5,17 & 5,08 & 5,02 \\
\hline Nutrientes digestíveis totais ${ }^{1}$ & 65,94 & 66,85 & 67,72 & 71,79 \\
\hline
\end{tabular}

Nas amostras dos alimentos fornecidos, das sobras e das fezes, foram determinados os teores de MS, MO, cinzas, nitrogênio total (Kjehldal) e EE (em aparelho Soxhlet), de acordo com metodologias descritas por Silva \& Queiroz (2002). Os teores de FDN, FDA e lignina foram estimados pelos métodos sugeridos por Van Soest et al., (1991) utilizando-se amilase sem adição de sulfito de sódio na determinação da FDN.

Os teores de carboidratos totais dos alimentos (CT) foram calculados segundo Sniffen et al. (1992): CT = $100-$ (\%PB + \%EE + \%Cinzas), e os não-fibrosos (CNF) foram estimados subtraindo da porcentagem total de carboidratos os teores de fibra em detergente neutro corrigida para cinzas e proteína $\left(\mathrm{FDN}_{\mathrm{cp}}\right): \mathrm{CNF}=\mathrm{CHO}-\mathrm{FDN}_{\mathrm{cp}}$. Os teores de nutrientes digestíveis totais (NDT) foram calculados conforme o NRC (2001), a partir das frações digestíveis $(d)$, segundo a equação: $\operatorname{NDT}(\%)=\mathrm{PB} d+2,25 \mathrm{EE} d+\mathrm{FDN} d+$ CNFd.

As vacas foram ordenhadas mecanicamente duas vezes ao dia e a produção de leite registrada por meio de dispositivo acoplado a ordenhadeira. A coleta das amostras de leite provenientes da ordenha da manhã e da tarde, constituídas de forma proporcional à produção de cada período, totalizando aproximadamente $250 \mathrm{~mL}$ cada, foi realizada no $18^{\circ}$ dia de cada período experimental, para análise dos teores de proteína bruta, gordura, extrato seco total e extrato seco desengordurado.

A produção de leite corrigida (PLC) para 3,5\% de gordura foi estimada segundo Sklan et al. (1992), pela seguinte equação: $\mathrm{PLC}=[(0,432+0,1625 \times \%$ gordura do leite $) \times$ produção de leite em kg/dia]. O teor de nitrogênio total da amostra de leite foi obtido a partir de análise pelo método micro Kjeldahl (Silva \& Queiroz, 2002), obtendo-se o teor de proteína bruta da amostra e multiplicando-se o teor de nitrogênio pelo fator 6,38. A determinação do extrato seco total e do extrato seco desengordurado foi feita pela técnica de Gerber (Behmer, 1984) e o teor de gordura foi determinado segundo Pregnolatto \& Pregnolatto (1985).

No $19^{\circ}$ dia de cada período experimental, foram feitas observações visuais das vacas para avaliação do comportamento ingestivo. A observação de cada animal ocorreu a cada dez minutos, durante 24 horas, para determinação dos tempos despendidos com alimentação, ruminação e ócio. No dia subsequente, foram realizadas a contagem do número de mastigações merícicas e a determinação do tempo despendido na ruminação de cada bolo ruminal, para cada animal, com a utilização de cronômetro digital. Os valores do tempo despendido e do número de mastigações merícicas por bolo ruminal foram obtidos a partir das observações feitas durante a ruminação de três 
bolos ruminais, em três períodos diferentes do dia (10 às 12 h; 14 às 16 h e 19 às 21 h). Durante a observação noturna dos animais, o ambiente foi mantido com iluminação artificial.

A eficiência de alimentação (EAL), a eficiência de ruminação (ERU), o número de bolos ruminais por dia (NBR), o tempo de mastigação total por dia (TMT) e o número de mastigações merícicas por dia (NMMnd) foram obtidos, segundo técnica descrita por Bürger et al. (2000).

Os dados foram submetidos à análise de variância, conforme o modelo matemático seguinte, utilizando-se o programa SAS 8.0 (SAS, 1991):

$\mathrm{Y}_{\mathrm{ijkl}}=\mu+\mathrm{V}_{\mathrm{i}}(\mathrm{l})+\mathrm{P}_{\mathrm{j}}(\mathrm{l})+\mathrm{T}_{\mathrm{k}}+\mathrm{Ql}+\mathrm{TQ}_{\mathrm{kl}}+\varepsilon_{\mathrm{ij}} \mathrm{l}$,

em que $\mathrm{Y}_{\mathrm{ijkl}}=$ observação na vaca $\mathrm{i}$, no período $\mathrm{j}$, submetida ao tratamento $\mathrm{k}$, no quadrado latino $\mathrm{l}, \mu=$ efeito geral da média; $V_{i(l)}=$ efeito da vaca $i$, dentro do quadrado latino $\mathrm{l}(\mathrm{i}=1,2,3,4) ; \mathrm{P}_{\mathrm{j}(\mathrm{l})}=$ efeito do período $\mathrm{j}$, dentro do quadrado latino l $(\mathrm{j}=1,2,3,4) ; \mathrm{T}_{\mathrm{k}}=$ efeito do tratamento $\mathrm{k}(\mathrm{k}=1,2,3,4) ; \mathrm{Q}_{1}=$ efeito do quadrado latino $\mathrm{l}(\mathrm{l}=1,2,3) ; \mathrm{T}_{\mathrm{Qkl}}=$ efeito da interação entre o tratamento k e o quadrado latino l; e $\varepsilon_{\mathrm{ijkl}}=$ erro aleatório associado a cada observação ijkl, eijkl $\sim \operatorname{NID}\left(0, \sigma^{2}\right)$. As médias foram comparadas pelo teste de Tukey a $5 \%$ de probabilidade.

\section{Resultados e Discussão}

A inclusão de caroço de algodão nas dietas não proporcionou ingestões semelhantes às obtidas com silagem de milho ( $\mathrm{P}>0,05)$, as quais foram 34 , 22 e $25 \%$ superiores (Tabela 2) às determinadas com a cana-de-açúcar contendo 0, 7 e 14\% de caroço de algodão, respectivamente. Resultados semelhantes foram observados em vários estudos realizados por Paiva et al. (1991), Pires et al. (1999), Magalhães et al. (2004) e Mendonça et al. (2004), que encontraram consumos de MS 16,4; 25,5; 16,1 e 21,4\%, respectivamente, maiores para dietas à base de silagem de milho em comparação a dietas contendo cana-de-açúcar como volumoso único para vacas leiteiras. Corrêa et al. (2003) analisaram cana-de-açúcar para vacas de leite com relação volumoso:concentrado de 45:55 e também observaram menores consumos em relação à silagem de milho, porém com magnitude de 6,52\%. Segundo Rodrigues (1999), somente dietas de cana-de-açúcar com relação volumoso:conncentrado menor que 45:55 podem propiciar consumos próximos aos da silagem de milho na relação volumoso:concentrado de 60:40.

A baixa digestibilidade da fibra pode ser uma causa da redução no consumo de cana-de-açúcar (Allen, 2000). Segundo Corrêa et al. (2003), em vacas de alta produção, o consumo de dietas contendo cana-de-açúcar apresentou comportamento quadrático e tendência de redução durante o período experimental; além disso, os consumos de silagem de milho e cana-de-açúcar foram próximos no começo de cada período (3,76 e 3,48\% do PV, respectivamente). Segundo os autores, esse comportamento permite supor que, com o enchimento do trato digestivo durante o período experimental, reduz o consumo de cana-de-açúcar e períodos experimentais longos podem enfatizar as diferenças entre essas forragens.

Apesar dos valores inferiores aos da silagem de milho, a inclusão de caroço de algodão ocasionou aumento na ingestão de MS de 1,58 kg/dia com 7\% de inclusão $(P<0,05)$, apesar de não-significativo, em torno de $1,10 \mathrm{~kg} /$ dia superior com $14 \%$, em relação à dieta com cana-de-açúcar sem caroço de algodão. Esses aumentos no consumo de MS refletiram em maiores ingestões de CNF para a dieta com 7\% e de EE e NDT para os dois níveis de caroço de algodão $(\mathrm{P}<0,05)$ em relação à cana-de-açúcar sem caroço de algodão.

A comparação das dietas com 7 e $14 \%$ de caroço de algodão comprova que, apesar de os consumos de MS

Tabela 2 - Ingestões de matéria seca e nutrientes

\begin{tabular}{|c|c|c|c|c|c|}
\hline \multirow[t]{2}{*}{ Item } & \multirow[t]{2}{*}{ Silagem de milho } & \multicolumn{3}{|c|}{ Nível de caroço de algodão na cana-de-açúcar } & \multirow[t]{2}{*}{$S_{\bar{X}}$} \\
\hline & & $0 \%$ & $7 \%$ & $14 \%$ & \\
\hline Matéria seca (kg/dia) & $20,81 \mathrm{a}$ & $15,53 c$ & $17,11 b$ & $16,63 \mathrm{bc}$ & 0,18 \\
\hline Matéria seca $(\% \mathrm{PV})^{1}$ & $3,98 a$ & $2,91 \mathrm{c}$ & $3,25 b$ & $3,07 \mathrm{bc}$ & 0,04 \\
\hline Matéria seca $\left(\mathrm{g} / \mathrm{kg}^{0,75}\right)$ & $190,08 a$ & $139,80 c$ & $155,49 b$ & $147,96 \mathrm{bc}$ & 1,76 \\
\hline Matéria orgânica (kg/dia) & $19,58 \mathrm{a}$ & $14,88 c$ & $16,39 b$ & $15,97 \mathrm{bc}$ & 0,17 \\
\hline Proteína bruta (kg/dia) & $3,26 a$ & $2,48 b$ & $2,67 b$ & $2,45 b$ & 0,03 \\
\hline Extrato etéreo (kg/dia) & $0,47 b$ & $0,24 d$ & $0,41 \mathrm{c}$ & $0,59 a$ & 0,01 \\
\hline Carboidratos totais (kg/dia) & $15,84 a$ & $12,16 \mathrm{~b}$ & $13,30 \mathrm{~b}$ & $12,93 \mathrm{~b}$ & 0,15 \\
\hline Fibra em detergente neutro (kg/dia) & $7,97 a$ & $5,42 b$ & $5,89 b$ & $5,63 b$ & 0,09 \\
\hline Fibra em detergente neutron $(\% \mathrm{PV})^{1}$ & $1,52 \mathrm{a}$ & $1,02 c$ & $1,12 b$ & $1,04 \mathrm{c}$ & 0,02 \\
\hline Carboidratos não-fibrosos (kg/dia) & $7,86 a$ & $6,74 b$ & $7,40 \mathrm{a}$ & $7,29 a b$ & 0,09 \\
\hline Nutrientes digestíveis totais (kg/dia) & $13,62 \mathrm{a}$ & $10,39 c$ & $11,58 b$ & $11,93 \mathrm{~b}$ & 0,12 \\
\hline
\end{tabular}

$\mathrm{S}_{\mathrm{x}}=$ erro-padrão da media.

Médias, nas linhas, seguidas de mesma letra não diferem estatisticamente pelo teste de Tukey a 5\% de probabilidade. 
serem estatisticamente semelhantes, existem diferenças em valores, que foram próximos a 0,55 kg/dia, ocasionando diferenças numéricas nos consumos de PB (0,22 kg/dia), FDN $(0,25 \mathrm{~kg} / \mathrm{dia})$ e CNF $(0,11 \mathrm{~kg} / \mathrm{dia})$. Parte dessas diferenças decorre da maior sobra de caroço de algodão no cocho dos animais mantidos com a dieta com $14 \%$ de caroço de algodão. Considerando as ingestões de MS e EE e os teores de EE das dietas e do caroço de algodão, não houve sobras de caroço de algodão entre os animais mantidos com as dietas com 7\% de caroço de algodão. No entanto, no nível de $14 \%$ de inclusão, as sobras de caroço de algodão no cocho foram de $200 \mathrm{~g} / \mathrm{dia}$, ou aproximadamente $15 \%$ de toda sobra observada diariamente.

O maior consumo $(\mathrm{P}<0,05)$ de FDN na dieta à base de silagem de milho em relação àquelas com cana-de-açúcar foi similar ao verificado nos trabalhos de Magalhães et al. (2004), Mendonça et al. (2004) e Costa et al. (2005), principalmente em decorrência do maior consumo de MS, uma vez que os teores de FDN das dietas foram próximos. Além disso, o consumo médio de FDN na dieta com silagem de milho (1,52\% PV) foi superior ao máximo considerado por Mertens (1985) de 1,2\% \pm 0,1 do PV, o qual sugere que o consumo é regulado, entre outros fatores, pelas características dos alimentos. Em dietas ricas em FDN e com menores concentrações energéticas, o consumo aumenta até que sejam atendidas as necessidades energéticas do animal, observando-se o limite de $1,2 \% \pm 0,1$ do PV em FDN para efeito de enchimento físico do rúmen.

Os resultados obtidos, tanto neste como em todos os experimentos revisados, evidenciam que dietas de canade-açúcar com relação volumoso:concentrado de 60:40 resultaram em consumos de FDN menores que 1,2\% $\pm 0,1$ do PV e que a inclusão de 7\% de caroço de algodão fez com que o consumo de FDN alcançasse valores próximos ao determinado por Mertens (1985).

O caroço de algodão, como toda suplementação com lipídios, requer avaliações frequentes do consumo, pois os animais tendem a diminuir a ingestão de matéria seca (Devendra \& Lewis, 1974). Entretanto, a adição de caroço de algodão não elevou o teor de extrato etéreo (máximo de $3,76 \%$ na MS) a níveis que poderiam comprometer a digestibilidade da fibra e diminuir a ingestão de alimentos. Palmquist (1995) recomenda limite máximo de 7\% e Van Soest (1994) de 8\% de EE em dietas para vacas lactantes.

Além dos teores de EE, a quantidade e degradabilidade da FDN, tanto do caroço de algodão quanto dos alimentos substituídos, pode determinar aumento ou redução no consumo. Segundo Pires et al. (1997), o teor e as características da fibra do caroço de algodão estão diretamente relacionados à presença do línter, uma estrutura de celulose de alta digestibilidade, que contribui com até $10 \%$ de seu peso. Além disso, o menor tamanho de partícula e a alta gravidade específica das fontes de fibra não-forragem aumentam a taxa de passagem ruminal e o consumo (Grant, 1997). Por outro lado, a FDN da cana-de-açúcar é de baixa digestibilidade, o que leva a maior tempo de retenção no rúmen e em todo trato digestivo (Preston, 1982; Rodriguez, 1995; Corrêa et al., 2003). Dessa forma, mesmo que o caroço de algodão não tenha sido processado, a adição de caroço de algodão levou à substituição da FDN da cana-de-açúcar por uma mais digestível, de maior taxa de passagem, aumentando os consumos de MS e FDN.

Esses aspectos podem ser confirmados por uma gama de resultados reportados. Brosh et al. (1989), trabalhando com bovinos; Teixeira \& Borges (2005), com ovinos; e Mello et al. (2006), com vacas leiteiras, observaram aumento de consumo de matéria seca quando incluíram caroço de algodão para animais em pastagem em substituição a palma forrageira e ao feno de capim-braquiária, respectivamente.

O consumo de FDN obtido com a dieta com 14\% de substituição da cana-de-açúcar por caroço de algodão não diferiu daquele encontrado com cana-de-açúcar sem caroço de algodão; da mesma forma, foi inferior ao preconizado por Mertens (1985). O baixo consumo neste caso parece estar relacionado aos mesmos mecanismos reguladores de consumo em dietas à base de cana-deaçúcar. É possível que os maiores teores de EE na cana-deaçúcar com 14\% de caroço de algodão tenham diminuído as taxas de degradação da FDN da cana-de-açúcar, provocando maior enchimento do trato digestivo e redução no consumo durante o período experimental (Corrêa et al., 2003).

Apesar de o experimento ter sido realizado em quadrado latino, o que impede análises de desempenho, foram feitas pesagens dos animais no início de cada período experimental. Foram verificados os seguintes valores de variação diária de peso corporal: 0,96 ; -0,62; 0,33; - $0,22 \mathrm{~kg} /$ dia, para a dieta à base de silagem de milho e para as dietas à base de cana-de-açúcar com 0, 7 e 14\% de caroço de algodão, respectivamente. Os valores de variação de peso obtidos com a cana-de-açúcar sem caroço de algodão e com a silagem de milho foram semelhantes aos encontrados por Paiva et al. (1991), Magalhães et al. (2004) e Costa et al. (2005). Nos animais alimentados com as dietas com caroço de algodão, o maior consumo de energia promoveu menor redução no peso corporal e até ganho de peso no caso da cana-de-açúcar com $7 \%$ de inclusão de caroço de algodão. A grande amplitude de variação no peso entre as dietas se deve, em parte, ao fato de as vacas não poderem, devido à lactação, ficar em jejum antes da pesagem. 
A grande variação no consumo de matéria seca entre as dietas nos períodos experimentais ocasiona variação de peso, em decorrência das quantidades de alimento no trato gastrintestinal. Segundo Davis (1993), variações no consumo de $0,45 \mathrm{~kg}$ de matéria seca por dia modificam o peso corporal das vacas em até $1,8 \mathrm{~kg}$.

Os coeficientes de digestibilidade da matéria seca e da matéria orgânica, bem como da proteína bruta e dos carboidratos totais da dieta, foram semelhantes em todas as dietas experimentais (Tabela 3 ).

Os dados obtidos com a silagem de milho e a cana-deaçúcar como volumoso estão de acordo com os de Mendonça et al. (2004), Magalhães et al. (2004) e Costa et al. (2005). Esses autores observaram em pesquisa com silagem de milho maiores $(\mathrm{P}<0,05)$ coeficientes de digestibilidade da FDN e do extrato etéreo e menor digestibilidade dos CNF em relação a uma dieta à base de cana-de-açúcar com relação volumoso:concentrado de 60:40. A maior digestibilidade do extrato etéreo se deve ao maior consumo desses compostos nas dietas com silagem de milho (Detmann et al., 2006). A menor quantidade $(4,21 \%$ vs $5,09 \%$ ) e a melhor digestibilidade da lignina nas dietas com silagem de milho em relação à cana-de-açúcar pode, em parte, explicar a melhor digestibilidade da FDN quando fornecidas essas dietas (Hoover, 1986). No caso dos carboidratos não-fibrosos, a menor digestibilidade se deve possivelmente ao maior consumo de MS quando fornecida silagem de milho.

Nas dietas com cana-de-açúcar, a inclusão de 14\% de caroço de algodão aumentou $(\mathrm{P}<0,05)$ a digestibilidade do extrato etéreo, que atingiu valores semelhantes aos obtidos com a silagem de milho. Segundo Detmann et al. (2006), a estimação da fração digestível do extrato etéreo da dieta é melhor caracterizada pelo pressuposto de constância no coeficiente de digestibilidade verdadeira e de diferenciação da contribuição metabólica de acordo com o nível de consumo. Assim, com o aumento do teor de lipídios na dieta, como neste estudo, a proporção desses compostos em relação à contribuição metabólica aumenta, melhorando o coeficiente de digestibilidade. Esses resultados corroboram os de diversos outros trabalhos em que a inclusão do caroço de algodão na dieta levou a aumento da digestibilidade do extrato etéreo (Smith et al., 1981; Luginbuhl et al., 2000; Fernandes et al., 2002).

A adição de caroço de algodão pode levar a diminuição da digestibilidade da FDN caso os níveis de EE sejam elevados. Devendra \& Lewis (1974) descreveram um possível mecanismo em que altas inclusões de gordura diminuem a ligação dos microrganismos ruminais à fibra, diminuindo a digestibilidade pela criação de uma barreira higroscópica. Trabalhos com inclusão de caroço de algodão em níveis inferiores a 7\% de extrato etéreo comprovam que não ocorre diminuição da digestibilidade do FDN (Smith et al. 1981; Luginbuhl et al., 2000; Fernandes et al., 2002). Em experimento em que o teor de extrato etéreo alcançou valores próximos ou superiores a 7\%, houve diminuição significativa da digestibilidade da FDN, como observado por Pena et al. (1986), Teixeira \& Borges (2005) e Coppock et al. (1987) em pesquisa com caroço de algodão em níveis superiores a $24 \%$.

As produções de leite sem correção (PL) e com correção para 3,5\% de gordura (PLC) de gordura e de proteína foram superiores e de aproximadamente $30 \%(\mathrm{P}<0,05)$ para a dieta à base de silagem de milho em relação àquela à base de cana-de-açúcar (Tabela 4). Grande número de pesquisas evidencia menores produções de leite por vacas de maior potencial de produção quando alimentadas com cana-deaçúcar em comparação à silagem de milho (Paiva et al., 1991; Pires et al., 1999; Magalhães et al., 2001; Corrêa et al., 2003). $\mathrm{Na}$ literatura, consta que as produções médias tidas com o fornecimento de cana-de-açúcar são aproximadamente $25 \%$ menores que da silagem de milho. No entanto, como relatado em diversos trabalhos, à medida que se diminuiu a relação volumoso:concentrado nas dietas com cana-deaçúcar a valores menores que 50:50, obtiveram-se produções de leite semelhantes às da silagem de milho na relação volmoso:concentrado 60:40 (Rodrigues et al., 1999; Mendonça et al., 2004; Costa et al., 2005).

Tabela 3 - Digestibilidade da matéria seca, matéria orgânica e dos nutrientes das dietas experimentais

\begin{tabular}{|c|c|c|c|c|c|}
\hline Item & SM & CA0 & CA 7 & CA14 & $S_{\bar{X}}$ \\
\hline Matéria seca, \% & 66,20 & 65,81 & 63,90 & 65,20 & 0,53 \\
\hline Matéria orgânica, \% & 67,55 & 67,35 & 65,36 & 66,43 & 0,47 \\
\hline Proteína bruta, \% & 68,70 & 68,49 & 65,01 & 65,26 & 0,59 \\
\hline Extrato etéreo, \% & $78,03 \mathrm{ab}$ & $74,14 b$ & $75,50 \mathrm{ab}$ & $80,75 a$ & 0,74 \\
\hline Fibra em detergente, \% & $45,79 a$ & $33,99 b$ & $29,73 b$ & $31,71 b$ & 0,82 \\
\hline Carboidratos não-fibrosos, \% & $87,83 b$ & $94,82 \mathrm{a}$ & $93,55 a$ & $93,46 a$ & 0,36 \\
\hline Carboidratos totais, \% & 66,91 & 67,68 & 64,97 & 65,78 & 0,38 \\
\hline
\end{tabular}

$\mathrm{S}_{\mathrm{x}}=$ erro-padrão da media.

Médias nas linhas seguidas de uma mesma letra não diferem estatisticamente pelo teste de Tukey a 5\% de probabilidade. 
Nas dietas à base de cana-de-açúcar, a inclusão de caroço de algodão proporcionou aumentos tanto na produção de leite quanto na produção de leite corrigida para gordura, cujo aumento foi em torno de $10 \%$. As respostas em produção e composição do leite parecem estar relacionadas à produção animal e à fase da lactação (Emery \& Herdt, 1991), ao nível de caroço de algodão e ao teor de extrato etéreo na dieta (Coppock et al., 1987), à quantidade e composição da FDN e à energia e degradabilidade da proteína da dieta (Arieli, 1998).

Alguns estudos não comprovaram aumentos na produção de leite corrigida quando utilizado caroço de algodão (Palmquist \& Conrad, 1978; Villela et al., 1996). No entanto, quando o caroço de algodão foi incluído em níveis moderados, dependendo do alimento substituído, houve aumento no teor de gordura ou na produção diária de gordura diária e na produção de leite corrigida (Smith et al., 1981; Coppock etal., 1987; Fernandes etal., 2002; de Melo et al., 2006). Apesar de a composição do leite ter sido semelhante entre as dietas com cana-de-açúcar, as produções diárias desses compostos foram maiores $(\mathrm{P}<0,05)$ naquelas dietas com caroço de algodão, em decorrência da maior produção de leite.

Dhiman et al. (1999), em pesquisa com vacas de alta produção consumindo dietas com caroço de algodão, verificaram tendência de diminuição na porcentagem de gordura do leite e redução de 0,045 unidade percentual no teor de proteína do leite a cada $100 \mathrm{~g}$ de ácido graxo consumido. Todavia, em razão da maior produção de leite pelos animais que receberam as dietas com caroço de algodão, a produção diária de proteína do leite foi 115 g maior que a observada nos animais mantidos com a dieta controle. Em outro trabalho, Mena et al. (2001), apesar de terem verificado menor porcentagem de proteína no leite de vacas alimentadas com $15 \%$ de caroço de algodão extrusado na dieta, não detectaram redução na porcentagem de gordura e na produção de leite sem e com correção para 3,5\% de gordura em relação à dieta controle.

Considerando o tempo despendido com a atividade de ruminação, a dieta contendo $14 \%$ de caroço de algodão foi superior $(\mathrm{P}<0,05)$ àquelas à base de silagem de milho $\mathrm{e}$ cana-de-açúcar como volumoso exclusivo (Tabela 5). Em parte, esse fato pode ser explicado pelo não-processamento do caroço de algodão, fornecido inteiro aos animais e sem retirada do línter. A similaridade nos tempos despendidos com alimentação e ruminação entre as vacas recebendo silagem de milho ou cana-de-açúcar como volumoso exclusivo foi observada também por Polli et al. (1995) e Pires et al. (1999).

Em decorrência do maior consumo de FDN pelos animais mantidos com a dieta com silagem de milho, esperava-se aumento nos tempos de ruminação (Welch \& Hooper, 1988). No entanto, além de o teor de FDN poder prever o consumo de nutrientes e o comportamento ingestivo dos animais, outros aspectos deveriam ser considerados, como o grau de indigestibilidade da FDN, o teor de fibra potencialmente degradável e a taxa de degradação desta fibra no rúmen (Nocek, 1997).

A dieta à base de silagem de milho, por apresentar maior consumo de MS e FDN e tempos semelhantes de alimentação e ruminação aos obtidos com a dieta canade-açúcar sem caroço de algodão, possibilitou maiores eficiências $(\mathrm{P}<0,05)$ de alimentação e de ruminação, tanto para a matéria seca como para a FDN (Tabela 6).

Os dados obtidos neste experimento são próximos aos descritos por Mendonça et al. (2004b), que verificaram tendência de maiores eficiências de alimentação da MS e da FDN e da ruminação da MS para dietas com silagem de milho em comparação à cana-de-açúcar com mesma relação volumoso:concentrado.

O tempo de mastigação total (TMT) foi semelhante em todas as dietas experimentais, porém houve tendência ( $\mathrm{P}>0,05)$ de menor tempo e menor número de bolos ruminais,

Tabela 4 - Produções médias e composição química do leite

\begin{tabular}{|c|c|c|c|c|c|}
\hline \multirow[b]{2}{*}{ Item } & \multirow[b]{2}{*}{ ilagem de milho } & \multicolumn{3}{|c|}{ Cana-de-açúcar } & \multirow[b]{2}{*}{$S_{\bar{X}}$} \\
\hline & & $\begin{array}{c}\text { Sem caroço } \\
\text { de algodão }\end{array}$ & $\begin{array}{c}\text { Com } 7 \% \text { de } \\
\text { caroço de algodão }\end{array}$ & $\begin{array}{c}\text { Com } 14 \% \text { de } \\
\text { caroço de algodão }\end{array}$ & \\
\hline Leite corrigido $3,5 \%$ gordura, $\mathrm{kg} / \mathrm{dia}$ & ia $27,0 \mathrm{a}$ & $18,9 \mathrm{c}$ & $21,1 b$ & $21,6 b$ & 0,36 \\
\hline Gordura do leite, \% & 3,94 & 3,56 & 3,92 & 3,80 & 0,07 \\
\hline kg/dia & $984,2 \mathrm{a}$ & $663,6 c$ & $770,7 \mathrm{~b}$ & $780,9 b$ & 14,69 \\
\hline Relação proteína:gordura & $0,784 b$ & $0,851 \mathrm{a}$ & $0,781 b$ & $0,800 \mathrm{ab}$ & 0,007 \\
\hline Extrato seco total, \% & 12,7 & 12,2 & 12,7 & 12,5 & 0,11 \\
\hline Extrato seco desengordurado, \% & 8,81 & 8,68 & 8,78 & 8,69 & 0,08 \\
\hline
\end{tabular}

Médias nas linhas seguidas de uma mesma letra não diferem estatisticamente pelo teste de Tukey a 5\% de probabilidade. 
Tabela 5 - Tempos despendidos (horas/dia) em alimentação, ruminação e ócio

\begin{tabular}{|c|c|c|c|c|c|}
\hline \multirow[b]{2}{*}{ Item } & \multirow[b]{2}{*}{ Silagem de milho } & \multicolumn{3}{|c|}{ Cana-de-açúcar } & \multirow[b]{2}{*}{$S_{\bar{X}}$} \\
\hline & & $\begin{array}{l}\text { Sem caroço } \\
\text { de algodão }\end{array}$ & $\begin{array}{c}\text { Com } 7 \% \text { de } \\
\text { caroço de algodão }\end{array}$ & $\begin{array}{c}\text { Com } 14 \% \text { de } \\
\text { caroço de algodão }\end{array}$ & \\
\hline Alimentação & 5,57 & 5,07 & 5,75 & 5,15 & 0,74 \\
\hline Ruminação & $8,73 b$ & $8,60 \mathrm{~b}$ & $8,96 a b$ & $9,76 a$ & 0,80 \\
\hline Ócio & 9,70 & 10,33 & 9,29 & 9,09 & 1,18 \\
\hline
\end{tabular}

$\mathrm{S}_{\mathrm{x}}=$ erro-padrão da media.

Médias, nas linhas, seguidas de mesma letra não diferem estatisticamente pelo teste de Tukey a 5\% de probabilidade.

Tabela 6 - Comportamento ingestivo de vacas leiteiras alimentadas com rações à base de silagem de milho ou cana-de-açúcar com caroço de algodão

\begin{tabular}{|c|c|c|c|c|c|}
\hline \multirow[b]{2}{*}{ Item } & \multirow[b]{2}{*}{ Silagem de milho } & \multicolumn{3}{|c|}{ Cana-de-açúcar } & \multirow[b]{2}{*}{$S_{\bar{X}}$} \\
\hline & & $\begin{array}{l}\text { Sem caroço } \\
\text { de algodão }\end{array}$ & $\begin{array}{c}\text { Com } 7 \% \text { de } \\
\text { caroço de algodão }\end{array}$ & $\begin{array}{c}\text { Com } 14 \% \text { de } \\
\text { caroço de algodão }\end{array}$ & \\
\hline $\begin{array}{l}\text { Consumo de fibra em detergente } \\
\text { neutro (kg/dia) }\end{array}$ & $7,97 \mathrm{a}$ & $5,42 b$ & $5,89 b$ & $5,63 \mathrm{~b}$ & 0,63 \\
\hline Eficiência de alimentação (gMS/hora) & $3975,40 a$ & $3101,70 b$ & $3118,60 b$ & $3275,70 b$ & 591,4 \\
\hline Eficiência de ruminação (gFDN/hora) & $976,63 a$ & $652,39 b$ & $664,30 \mathrm{~b}$ & $580,37 b$ & 122,1 \\
\hline Tempo de mastigação total (horas/dia) & 14,30 & 13,67 & 14,71 & 14,90 & 1,18 \\
\hline Número de bolos ruminais ( $\mathrm{n}^{\circ} / \mathrm{dia}$ ) & 647,71 & 598,35 & 626,07 & 673,55 & 77,20 \\
\hline Mastigações merícicas (nºdia) & $34.985 \mathrm{ab}$ & $33.335 b$ & $36.527 \mathrm{ab}$ & $39.196 \mathrm{a}$ & $4.594,0$ \\
\hline Mastigações merícicas por bolo (nºbolo) & 54,35 & 56,85 & 60,15 & 61,01 & 7,10 \\
\hline Tempo de ruminação por bolo (seg/bolo) & 49,02 & 52,49 & 52,70 & 54,28 & 6,22 \\
\hline
\end{tabular}

$\mathrm{S}_{\mathrm{x}}=$ erro-padrão da media.

Médias, nas linhas, seguidas de uma mesma letra não diferem estatisticamente pelo teste de Tukey, a 5\% de probabilidade.

além de menor número de mastigações merícicas por dia (NMMnd; $\mathrm{P}<0,05$ ) para a dieta à base de cana-de-açúcar sem caroço de algodão. Essas observações podem estar relacionadas ao menor consumo de matéria seca observado com o fornecimento dessa dieta.

Não houve diferença na eficiência de ruminação da FDN das dietas à base de cana-de-açúcar, porém verificou-se tendência $(\mathrm{P}=0,08)$ de menor eficiência com $14 \%$ de inclusão de caroço de algodão. Uma das razões pode ser a tendência de maior número de mastigações por bolo ruminal $(\mathrm{P}=0,09)$ e o maior número de mastigações merícicas por dia $(\mathrm{P}<0,05)$ no maior nível de inclusão de caroço de algodão, que promoveram maior tempo de ruminação e menor eficiência na ruminação. A falta de processamento do caroço de algodão (quebra e retirada do línter), segundo Pires et al. (1997), ocasiona aumento nos teores de FDN fisicamente efetiva da dieta, forçando o animal a aumentar o número de mastigações por dia.

\section{Conclusões}

A inclusão de caroço de algodão nas dietas com canade-açúcar melhora os consumos de matéria seca e nutrientes, o desempenho, a produção de leite e de leite corrigida para gordura e a composição do leite, no entanto, os benefícios dessas dietas não se equiparam aos da dieta com silagem de milho. Entre as dietas com cana-de-açúcar, a inclusão de $7 \%$ de caroço de algodão na cana-de-açúcar mostra-se de melhor aplicabilidade em relação à de $14 \%$. Apesar de a dieta cana-de-açúcar com $14 \%$ de caroço de algodão apresentar teores baixos e aceitáveis de extrato etéreo e produções de leite semelhantes aos da dieta com $7 \%$ de caroço de algodão, ocasiona variação de peso negativa e tendência de menores consumos de matéria seca e maiores tempos em ruminação.

\section{Literatura Citada}

ABEL-CAINES, S.F.; GRANT, R.J.; HADDAD, S.G. Whole cottonseeds or a combination of soybeans and soybean hulls in the diets of lactating dairy cows. Journal of Dairy Science, v.80, p.1353-1357, 1997.

ALLEN, M.S. Effects of diet on short-term regulation of feed intake by lactating cattle. Journal of Dairy Science, v.83, p.1598-1624, 2000.

ARIELI, A. Whole cottonseed in dairy cattle feeding: a review. Animal Feed Science and Technology, v.72, p.97-110, 1998. 
BEHMER, M.L.A. Tecnologia do leite: produção, industrialização e análise. 13.ed. São Paulo: Nobel, 1984. p.100-108.

BROSH, A.; HOLZER, Z.; LEVY, D. Cottonseed for protein and energy supplementation of high - roughage diets for beef cattle. Animal Production, v.48, p.513-518, 1989.

BÜRGER, P.J.; PEREIRA, J.C.; QUEIROZ, A.C. et al. Comportamento ingestivo em bezerros holandeses alimentados com dietas contendo diferentes níveis de concentrado. Revista Brasileira de Zootecnia, v.29, n.1, p.236-242, 2000.

CANT, J.P.; DEPTERS, E.J.; BALDWING, R.L. Mammary uptake of energy metabolites in dairy cows fed fat and its relationship to milk protein depression. Journal of Dairy Science, v.76, n.8, p.2254-2265, 1993.

COPPOCK, C.E.; LANHAM, J.K.; HORNER, J.I. A review of the nutritive value and utilization of whole cottonseed, cottonseed meal and associated by-products by dairy cattle. Animal Feed Science and Technology, v.18, p.89-129, 1987.

COPPOCK, C.E.; WEST, J.W.; MOYA, J.R. et al. Effects of amount of whole cottonseed on intake, digestibility, and physiological responses of dairy cows. Journal of Dairy Science, v.68, p.2248-2258, 1985.

CORREAA, C.E.S.; PEREIRA, M.N.; OLIVEIRA, S.G. et al. Performance of holtein cows fed sugar cane or corn silages of different grain textures. Scientia Agricola, v.60, n.4, p.621-629, 2003.

COSTA, M.G.; CAMPOS, J.M.S.; VALADARES FILHO, S.C. et al. Desempenho produtivo de vacas leiteiras alimentadas com diferentes proporções de cana-de-açúcar e concentrado ou silagem de milho na dieta. Revista Brasileira de Zootecnia, v.34, n.6, p.2437-2445, 2005.

CRAIG, W.M.; HONG, B.J.; BRODERICK, G.A. et al. In vitro inoculum enriched with particle associated microorganisms for determining rates of fiber digestion and protein degradation. Journal of Dairy Science, v.50, n.4, p.523-526, 1984.

DADO, R.G.; ALLEN, M.S. Intake limitations, feeding behavior, and rumen function of cows challenged with rumen fill from dietary fiber or inert bulk. Journal of Dairy Science, v.78, n.1, p.118-133, 1995.

DAVIS, C.L. Alimentación de la vaca lechera alta productora. Dundee: Milk Specialties Company, University of Illinois, 1993. $59 \mathrm{p}$.

DEVENDRA, C.; LEWIS, D. The interaction between dietary lipids and fiber in the sheep. Animal Production, v.59, p.67, 1974.

DE MELO, A.A.S.; FERREIRA, M.A.; VÉRAS, A.S.C. et al. Desempenho leiteiro de vacas alimentadas com caroço de algodão em dieta à base de palma forrageira. Pesquisa Agropecuária Brasileira, v.41, n.7, p.1165-1171, 2006.

DHIMAN, T.R.; ANAND, G.R.; SATTER, L.D. et al. Conjugated linoleic acid content of milk from cows fed different diets. Journal of Dairy Science, v.82, n.10, p.2146 2156, 1999.

ELLIOTT, J.P.; DRACKLEY, J.K.; SCHAUFF, D.J. et al. Diets containing high oil corn and tallow for dairy cows during early lactation. Journal of Dairy Science, v.76, n.3, p.775-789, 1993.

EMERY, R.S.; HERDT, T.H. Lipid nutrition. The Veterinary Clinics of North America, v.7, p.341-352, 1991.

FERNANDES, J.J.R.; PIRES, A.V.; SIMAS, J.M.C. et al. Efeito de níveis de caroço de algodão na dieta de vacas holandesas em lactação In: REUNIÃO ANUAL DA SOCIEDADE BRASILEIRA DE ZOOTECNIA, 37., 2000, Viçosa, MG. Anais... Viçosa, MG: Sociedade Brasileira de Zootecnia, 2000. p.433.

GRANT, R.J. Interactions Among Forages and Nonforage Fiber Sources. Journal of Dairy Science, v.80, p.1438-1446, 1997.

HARVATINE D.I.; WINKLER J.E.; DEVANT-GUILLE, M. et al. Whole linted cottonseed as a forage substitute: Fiber effectiveness and digestion kinetics. Journal of Dairy Science, v.85, n.8, p.1988-1999, 2002.

HAWKINS, G.E.; CUMMINS, K.A.; SILVEIO, M. et al. Physiological effects of whole cottonseed in the diet of lactating dairy cows. Journal of Dairy Science, v.68, n.10, p.2608-2614, 1985.
HOOVER, W.H. Chemical factors involved in ruminal fiber digestion. Journal of Dairy Science, v.69, n.10, p.2755-2766, 1986.

LUGINBUHL, J.M.; POORE, M.H.; CONRAD, A.P. Effect of level of whole cottonseed on intake, digestibility, and performance of growing male goats fed hay-based diets. Journal of Animal Science, v.78, p.1677-1683, 2000.

MAGALHÃES, A.L.R.; CAMPOS, J.M.S.; VALADARES FILHO, S.C. et al. Cana-de-açúcar em substituição à silagem de milho em dietas para vacas em lactação: desempenho e viabilidade econômica. Revista Brasileira de Zootecnia, v.33, n.5, p.1292-1302, 2004.

MENA, H.; SANTOS, J.E.P.; HUBER, J.T. et al. The effects of feeding varying amounts of gossypol from whole cottonseed and cottonseed meal in lactating dairy cows. Journal of Dairy Science, v.84, n.10, p.2231-2239, 2001.

MENDONÇA, S.S. Consumo, digestibilidade aparente, produção e composição do leite e variáveis ruminais em vacas leiteiras alimentadas com dietas à base de cana-de-açúcar. Revista Brasileira de Zootecnia, v.33, n.2, p.481-492, 2004.

MERTENS, D.R. Factors influencing feed intake in lactating cows: From theory to application using neutral detergent fiber. In: NUtRition CONFEREnCE, 46., 1985, Athens. Proceedings... Athens: University of Georgia, 1985. p.1-18.

NATIONAL RESEARCH COUNCIL - NRC. Nutrient requirements of dairy cattle. 7.ed. Washington, D.C.: National Academy Press, 2001. 381p.

NOCEK, J.E. In situ e outros métodos para estimar a proteína ruminal e a digestibilidade da energia. In: SIMPÓSIO INTERNACIONAL DE DIGESTIBILIDADE EM RUMINANTES. Anais... Lavras: UFLA - FAEPE, p.241-287, 1997.

NUSSIO, L.G. Milho e sorgo para a produção de silagens. In: PEIXOTO, A.M., MOURA, J.C.; FARIA, V.P. (Eds.) Volumosos para bovinos. Piracicaba: Fundação de Estudos Agrários Luiz de Queiroz, 1993. p.75-177.

PAIVA, J.A.J.; MOREIRA, H.A.; CRUZ, G.M. et al. Cana-de-açúcar associada à uréia/sulfato de amônio como volumoso exclusivo para vacas em lactação. Revista Brasileira de Zootecnia, v.20, n.1, p.90-99, 1991.

PALMQUIST, D.L. Suplementação de lipídios para vacas em lactação. In: PEIXOTO, A.M., MOURA, J.C., FARIA, V.P. (Eds.) Nutrição de bovinos. Piracicaba: Fundação de Estudos Agrários Luiz de Queiroz, 1995. p.321-338.

PALMQUIST, D.L.; CONRAD, H.R. High fat rations for dairy cows. effects on feed intake, milk and fat production, and plasma metabolites. Journal of Dairy Science, v.61, p.890-901, 1978.

PENA, F.; TAGARI, H.; SATTER, L.D. The effect of heat treatment of whole cottonseed on site and extent of protein digestion in dairy cows. Journal of Animal Science, v.62, n.5, p.1423-1433, 1986.

PIRES, A.V.; EASTRIDGE, M.L.; FIRKINS, J.L. Effects of heat treatment and physical processing of cottonseed on nutrient digestibility and production performance by lactating cows. Journal of Dairy Science, v.80, n.8, p.1685-1694, 1997.

PIRES, A.V.; SIMAS, J.M.C.; ROCHA, M.H.M. et. al. Efeito da substituição da silagem de milho pela cana-de-açúcar no consumo de matéria seca, parâmetros ruminais, produção e composição do leite de vacas holandesas. In: REUNIÃO ANUAL DA SOCIEDADE BRASILEIRA DE ZOOTECNIA, 36., 1999, Porto Alegre. Anais... Porto Alegre: Sociedade Brasileira de Zootecnia/ Gmosis, [1999]. (CD-ROM).

POLLI, V.A.; RESTLE, J.; SENNA, D.B. Comportamento de bovinos e bubalinos em regime de confinamento. I. Atividades. Ciência Rural, v.25, p.127-131, 1995.

PREGNOLATTO, W.; PREGNOLATO, N.P. Normas analíticas do Instituto Adolfo Lutz: métodos químicos e físicos para análise de alimentos. 3.ed. São Paulo: Instituto Adolfo Lutz, v.1, 1985. p.533. 
PRESTON, T.R. Nutritional limitations associated with the feeding of tropical forages. Journal of Animal Science, v.54, n.4, p.877-884, 1982.

RODRIGUES, A.A. Potencial e limitações de dietas à base de canade-açúcar e uréia para recria de novilhas e para vacas em lactação. In: SIMPÓSIO MINEIRO DE NUTRIÇÃO DE GADO DE LEITE, 2., 1999, Belo Horizonte. Anais... Belo Horizonte: Universidade Federal de Minas Gerais, 1999. p.66-75.

RODRIGUEZ, N.M. Pesquisas sobre dinâmica da fermentação ruminal e partição da digestão realizadas no Departamento de Zootecnia da Escola de Veterinária da UFMG. In: SIMPÓSIO INTERNACIONAL SOBRE EXIGÊNCIAS NUTRICIONAIS DE RUMinantes, 1995, Viçosa, MG. Anais... Viçosa, MG: Universidade Federal de Viçosa, 1995. p.355-388.

SKLAN, D.; ASHKENAZI, R.; BRAUN, A. et al. Fatty acids, calcium soaps of fatty acids and cottonseeds fed to high yielding cows. Journal of Dairy Science, v.75, n.9, p.2463 2472, 1992.

SILVA, D.J.; QUEIROZ, A.C. Análise de alimentos (métodos químicos e biológicos). 2.ed. Viçosa, MG: UFV/Imprensa Universitária, 2002. 235p.

SILVA, S.C. A cana-de-açúcar como alimento volumoso suplementar. In: PEIXOTO, A.M.; MOURA, J.C.; FARIA, V.P. (Eds.) Volumosos para bovinos. Piracicaba: Fundação de Estudos Agrários Luiz de Queiroz, 1993. p.59-74.

SMITH, N.E.; COLLAR, L.S.; BATH, D.L. et al. Digestibility and effects of whole cottonseed fed to lactating cows. Journal of Dairy Science, v.64, p.2209-2215, 1981.
SNIFFEN, C.J.; O’CONNOR, J.D.; VAN SOEST, P.J. et al. A net carbohydrate and protein system for evaluating cattle diets; II. Carbohydrate and protein availability. Journal of Animal Science, v.70, n.11, p.3562-3577, 1992.

STATISTICAL ANALYSIS SYSTEM - SAS. SAS Systems for linear models. Cary: SAS Institute, 1991. 329p.

TEIXEIRA, D.A.B.; BORGES, I. Efeito do nível de caroço integral de algodão sobre o consumo e digestibilidade aparente da fração fibrosa do feno de braquíaria (Brachiaria decumbens) em ovinos. Arquivos Brasileiros de Medicina Veterinária e Zootecnia, v.57, n.2, p.229-233, 2005.

VALADARES FILHO, S.C.; ROCHA JR., V.R.; CAPPELLI, E.R. Tabelas brasileiras de composição de alimentos para bovinos. Viçosa, MG: Universidade Federal de Viçosa, 2002. 297p.

VAN SOEST, P.J. Nutritional ecology of the ruminant. 2.ed. Ithaca: Cornell, 1994. 476p.

VAN SOEST, P.J.; ROBERTSON, J.D.; LEWIS, B.A. Methods for dietary fiber, neutral detergent fiber, nonstarch polysaccharides in relation to animal nutrition. Journal of Dairy Science, v.74, p.3583-3597, 1991.

VILLELA, S.D.J.; VALADARES FILHO, S.C.; SILVA, J.F.C. et al. Caroço de algodão para vacas leiteiras. 2. Efeito na digestão total e parcial dos nutrientes, taxa de passagem da digesta ruminal e degradação da matéria seca e proteína. Revista Brasileira de Zootecnia, v.26, n.1, p.186-194, 1997.

WELCH, J.G.; HOOPER, A.P. Ingestion of feed and water. In: CHURCH, D.C. (Ed.) The ruminant animal: digestive physiology and nutrition. Englewood Cliffs: Reston., 1988. p.108-116. 